\title{
Relationship of body condition score and live weight with body composition in mature Churra ewes
}

\author{
P. Frutos, A. R. Mantecón and F. J. Giráldez \\ Estación Agrícola Experimental, CSIC León, Spain
}

\begin{abstract}
Thirty-five mature Churra ewes, ranging in live weight from 30.3 to $52.6 \mathrm{~kg}$ and in body condition score from 1.25 to 4.00 were used to study the relationship between body condition score (BCS), live weight (LW) and body composition and fat distribution in ewes of this breed, which is one of the major sheep breeds of northern Spain. The procedure at slaughter and at subseguent dissection was designed to partition each body into two components, carcass and 'non-carcass'. Right side carcasses and 'non-carcass' components were used to analyse the chemical composition. From the left side of the lumbar region a joint was cut and dissected into muscle, bone, subcutaneous and intermuscular fat. According to the results obtained, omental fat represented the highest proportion of total internal fat regardless of the level of fatness. Distribution of internal fat was similar to that observed in other milk production breeds. Regressions on LW explained more of the variation than those on BCS for individual internal fat depots and chemically determined 'non-carcass' fat. The prediction of total body fat afforded by $L W$ was better than that provided by BCS. The subcutaneous and intermuscular fat depots in the lumbar joint were well correlated with $B C S$, carcass fat and total fat in the body, validating the use of this region for assessing BCS in Churra ewes. Nevertheless, the correlation coefficient with the omental depot was not statistically significant. The results of this study suggest that BCS was not as accurate for estimating body composition and fat depots in mature Churra ewes as has been shown previously in other breeds. The single most effective prediction index was LW. However, the utilization of both BCS and LW together provided more accurate estimations.
\end{abstract}

Keywords: body composition, body condition score, ewes, live weight.

\section{Introduction}

In most sheep production systems under arid or semi-arid conditions, the ability of the animal to retain and mobilize body reserves is of considerable importance in determining the sheep's productivity or even its survival (Russel et al., 1971). In such extensive conditions, a method for estimating body composition in a simple way would prove extremely useful.

Body condition was defined by Murray (1919) and a system for describing it in sheep, based on a fivepoint scale assessed by palpation of the lumbar region, was devised by Jefferies (1961). The lumbar region was proposed by these authors because the loin is the last part of the growing animal to develop; it is the last to put on fat and the first to lose it. Russel et al. (1969), using an adaptation of the Jefferies technique, showed that body condition score
(BCS) was related closely to the proportion of chemical fat in the body.

The system is considered a good predictor of the level of fatness and has proved very useful in quantifying relationships between body condition and certain production parameters. Since it is a simple system, it has been used in many aspects of sheep husbandry and management.

On the other hand, it is accepted that individual breeds have a distinctly different distribution of fat within the body (Taylor et al., 1989) and relationships derived from studies in one breed cannot be applied with confidence to others.

This experiment was carried out with the aim of studying the relationship between body condition score, live weight and body composition and fat 
distribution in mature ewes of the Churra breed. This breed is one of the major sheep breeds of northern Spain and its most important function is milk production. As an autochtonous breed, and because of the environment in which it is kept in which food availability undergoes significant seasonal changes, it is well adapted to the utilization of natural resources through mobilization of its body reserves.

\section{Material and methods}

The study was conducted using 35 non-pregnant, non-lactating mature Churra ewes (averaging 5 to 7 years of age), ranging in live weight (LW) from 30.3 to $52.6 \mathrm{~kg}$ and in body condition score (BCS) from 1.25 to 4.00 . Body condition score was assessed to nearest 0.25 score using the Russel et al. (1969) technique which employs a 0 to 5 score. The animals belonged to the flock of the research farm of the Spanish Council for Scientific Research (CSIC) in León (Spain). Before slaughter, the ewes were shorn and weighed without having been fed overnight and the BCS assessed independently by two experienced people.

The sheep were slaughtered by exsanguination from the jugular vein, after being injected intravenously with $1 \mathrm{ml}$ Xilocain (Rompum ${ }^{\circledR}$ ). Blood collected was not analysed but was assumed to contain proportionately 0.80 water, 0.183 protein and negligible amounts of fat (Agricultural Reseach Council, 1980). The procedure at slaughter and at subsequent dissection was designed to partition each body into two components, carcass and 'noncarcass'.

The gastrointestinal tract was emptied and its contents weighed in order to obtain the fleece-free empty body (FFEB) weight. The fatty tissues surrounding the alimentary tract (omental and mesenteric fat) were removed, along with any associated connective tissue, and weighed. Kidney and pelvic fat was also weighed after removal of the kidneys. Finally, all the internal fat depots and the gastrointestinal tract were added to the 'non-carcass' fraction.

Carcasses were divided down the backbone: both sides of each carcass were weighed while warm and again 1 day later when cold. Right sides were used to study the chemical composition. From the left side of the lumbar region (which was palpated to assess body condition score) a joint was cut from between the 2 nd and $3 r d$ to the 6th and 7th lumbar vertebrae and dissected into muscle, bone, subcutaneous and intermuscular fat. Weight losses occurring during dissection were considered to be proportional to each component.

Right side carcasses and 'non-carcass' components were stored in separate polyethylene bags at $-20^{\circ} \mathrm{C}$ until preparation for analysis. After thawing, they were cut into pieces and minced successively, using a blender fitted with end plates containing holes of $7 \mathrm{~mm}$ and $4 \mathrm{~mm}$ diameter. The mince was then mixed thoroughly and subsamples freeze dried to determine water content.

All samples were analysed for crude protein and ash by the Association of Official Analytical Chemists (1984) procedures. Fat content of carcass and 'noncarcass' was estimated by difference. The chemical composition was calculated assuming that all weight losses occurring during freezing and storage were $100 \%$ water.

Statistical analysis was conducted using GENSTAT 5 (Lawes Agricultural Trust, 1993). Regression analysis was used to evaluate relationships between BCS, LW and a combination of both to several body components. Correlation analysis was used to relate subcutaneous fat and subcutaneous plus intermuscular fat in the dissected lumbar joint with the weight of individual fat depots of ewes.

\section{Results}

Table 1 shows means and standard errors of the characteristics measured. The full range of BCS (from 0 to 5) was not represented at slaughter; however, the range of BCS from 1.25 to 4.00 as well as the range of LW are representative of those generally found in ewes of the Churra breed.

BCS and LW were correlated, with a correlation coefficient of $0.683 \quad(P<0.001)$. The regression equation for estimating $\mathrm{LW}$ from BCS indicated that per unit change in BCS, a corresponding change of $5.57 \mathrm{~kg}$ of LW could be expected:

$$
\begin{gathered}
\mathrm{LW}=30 \cdot 12(\text { s.e. } 2 \cdot 467)+5 \cdot 57(\text { s.e. } 1 \cdot 004) \mathrm{BCS} ; \\
\text { s.e. }=4 \cdot 27
\end{gathered}
$$

The omental fat depot represented the highest proportion (mean 0.438 , s.e. 0.0186) of the total internal fat (kidney and pelvic depot plus omental depot plus mesenteric depot). This was the case for the whole range of BCS and LW values studied. The mesenteric fat depot represented a higher proportion of internal fat at low BCS. In contrast, kidney and pelvic fat depot represented a higher proportion of the total internal fat at high levels of total fatness, as indicated in equations given in Table 2. 
Chemical non-carcass fat represented a high proportion of the FFEB fat in ewes of the Churra

Table 1 Means and standard errors of characteristics measured (no. $=35$ ) (all values denote means for individual sheep)

\begin{tabular}{|c|c|c|}
\hline & Mean & s.e. \\
\hline Live weight $(\mathrm{kg})$ & $43 \cdot 22$ & 0.990 \\
\hline Body condition score & $2 \cdot 35$ & 0.123 \\
\hline \multicolumn{3}{|l|}{ Kidney and pelvic fat: } \\
\hline weight $(\mathrm{g})$ & 528.8 & $54 \cdot 02$ \\
\hline proportion in total internal fat & 0.227 & 0.0122 \\
\hline \multicolumn{3}{|l|}{ Omental fat: } \\
\hline weight $(\mathrm{g})$ & $1041 \cdot 0$ & $124 \cdot 12$ \\
\hline proportion in total internal fat & 0.439 & 0.0188 \\
\hline \multicolumn{3}{|l|}{ Mesenteric fat: } \\
\hline weight $(g)$ & $686 \cdot 3$ & $50 \cdot 36$ \\
\hline proportion in total internal fat & 0.334 & 0.0168 \\
\hline Total internal fat $(g)$ & $2256 \cdot 2$ & $206 \cdot 16$ \\
\hline \multicolumn{3}{|l|}{ Non-carcass fat: } \\
\hline weight $(\mathrm{g})$ & 3231.9 & $251 \cdot 32$ \\
\hline proportion in the FFEB fat & 0.416 & 0.0104 \\
\hline \multicolumn{3}{|l|}{ Carcass fat: } \\
\hline weight $(g)$ & $4548 \cdot 4$ & $347 \cdot 14$ \\
\hline proportion in the carcass weight & 0.241 & 0.0126 \\
\hline proportion in the FFEB fat & 0.582 & $0 \cdot 0104$ \\
\hline \multicolumn{3}{|l|}{ Fleece-free empty body (FFEB): } \\
\hline weight $(g)$ & $33312 \cdot 8$ & 976.78 \\
\hline dry matter $(\mathrm{g})$ & $14912 \cdot 2$ & $701 \cdot 70$ \\
\hline fat $(g)$ & $7772 \cdot 3$ & $567 \cdot 37$ \\
\hline protein (g) & $5127 \cdot 6$ & $130 \cdot 68$ \\
\hline ash $(\mathrm{g})$ & $2002 \cdot 3$ & 56.92 \\
\hline \multicolumn{3}{|l|}{ Lumbar joint (proportion of): } \\
\hline subcutaneous fat & $0 \cdot 118$ & 0.0127 \\
\hline intermuscular fat & 0.090 & 0.0057 \\
\hline muscle & 0.516 & 0.0114 \\
\hline bone & 0.275 & $0 \cdot 0128$ \\
\hline
\end{tabular}

breed analysed in this experiment (mean 0.416, s.e. $0.0104)$. Carcass fat was proportionately only about 0.58 of the total fat weight and 0.24 of the carcass weight (mean 0.241 ; s.e. 0.0127 ).

Estimates of parameters for prediction equations for estimating weight of fat depots and FFEB composition of ewes of the Churra breed from BCS and from LW and correlation coefficients are presented in Table 2. As shown in that table, similar $R^{2}$ values were observed when either BCS or LW were used to predict kidney and pelvic fat depot weight. Variation in weights of omental fat depot, mesenteric fat depot and total internal fat was more accurately predicted by equations involving LW than with BCS. Including both BCS and LW in the regression model only significantly improved the model for estimating the weight of kidney and pelvic fat depot.

LW accounted for more of the variation in noncarcass fat, with essentially no improvement in the regression model when both $\mathrm{BCS}$ and $\mathrm{LW}$ were included. BCS accounted for more variation in carcass fat weight $\left(R^{2}=0 \cdot 70\right)$ than did LW $\left(R^{2}=0 \cdot 64\right)$. Inclusion of both fitted terms together (BCS and LW) improved the accuracy of its estimation $\left(R^{2}=0.79\right)$.

Chemical composition of the FFEB was better predicted using LW than using BCS. Variation in LW accounted for more of the variation in dry matter, fat, protein and ash contents $(0.77,0.72,0.65$ and 0.26 , respectively) than did $\mathrm{BCS}(0.58,0.64,0.27$ and 0.004 , respectively for dry matter, fat, protein and ash. Table 2).

Table 2 Estimates of parameters for prediction equations for estimating weight $(g)$ of fat depots and fleece-free empty body composition of ewes of Churra breed from body condition score (BCS, condition score units) and from live weight ( $L W, g)\left(S_{a}\right.$ and $S_{b}$ are standard errors of estimated parameters; s.e. is standard error of observations). All $\mathrm{R}^{2}$ values are significant $(\mathrm{P}<0.001)$ except those indicated

\begin{tabular}{|c|c|c|c|c|c|c|c|c|c|c|c|c|c|}
\hline & \multicolumn{6}{|c|}{ BCS } & \multicolumn{6}{|c|}{ LW } & \multirow{2}{*}{$\frac{\mathrm{LW}+\mathrm{BC}}{R^{2}}$} \\
\hline & $a$ & $S_{a}$ & $b$ & $S_{b}$ & s.e. & $R^{2}$ & $a$ & $S_{a}$ & $b$ & $S_{b}$ & s.e. & $R^{2}$ & \\
\hline \multicolumn{14}{|l|}{ Kidney and } \\
\hline Omental fat & 51 & 390 & 421 & 159 & 677 & $0 \cdot 15^{a}$ & -2355 & 741 & 0.078 & $0 \cdot 0170$ & 581 & 0.38 & 0.36 \\
\hline Mesenteric fat & 112 & 140 & 244 & $56 \cdot 8$ & 242 & $0 \cdot 34$ & -1122 & 219 & 0.042 & 0.0050 & 172 & 0.67 & 0.66 \\
\hline Total internal fat & -70 & 575 & 990 & 234 & 997 & 0.33 & -4721 & 997 & $0 \cdot 161$ & 0.0229 & 781 & 0.59 & 0.58 \\
\hline 'Non-carcass' fat & 166 & 661 & 1307 & 269 & 1145 & 0.41 & -5337 & 1179 & 0.199 & 0.0271 & 922 & 0.62 & 0.62 \\
\hline Carcass fat & -995 & 654 & 2359 & 266 & 1134 & 0.70 & -7667 & 1573 & 0.283 & 0.0361 & 1233 & 0.64 & 0.79 \\
\hline \multicolumn{14}{|l|}{$\begin{array}{l}\text { Fleece-free } \\
\text { empty body }\end{array}$} \\
\hline Dry matter & 4789 & 1151 & 4316 & 631 & 2687 & 0.58 & -11769 & 2528 & 0.618 & 0.0581 & 1978 & 0.77 & 0.82 \\
\hline Fat & -823 & 1156 & 3665 & 470 & 2003 & 0.64 & -13018 & 2288 & $0 \cdot 482$ & 0.0526 & 1790 & 0.72 & $0 \cdot 80$ \\
\hline Protein & 3800 & 381 & 566 & 155 & 660 & 0.27 & 554 & 585 & $0 \cdot 106$ & 0.0134 & 457 & 0.65 & $0 \cdot 64$ \\
\hline Ash & 1805 & 194 & 84 & 78.9 & 336 & $0.004^{b}$ & 694 & 370 & 0.030 & 0.0085 & 289 & $0 \cdot 26$ & 0.31 \\
\hline
\end{tabular}

a $P<0.01$.

b $P>0.05$. 
Table 3 Estimates of parameters for prediction equations for estimating weight of fat depots and fleece-free empty body (FFEB) composition of ewes of Churra breed, using both body condition score (BCS) and live weight (LW) and/or fitting logarithmic variates( $S_{a}$, $\mathrm{S}_{\mathrm{b}}$ and $\mathrm{S}_{\mathrm{c}}$ are standard errors of estimated parameters; s.e. is standard error of observations)

\begin{tabular}{|c|c|c|c|c|c|c|c|c|}
\hline & $a$ & $S_{a}$ & $b$ & $S_{b}$ & $c$ & $S_{c}$ & s.e. & $R^{2}$ \\
\hline \multicolumn{9}{|c|}{ Equation: component $\log Y(\mathrm{~g})=a+b \log \mathrm{LW}(\mathrm{g})$} \\
\hline Mesenteric fat & -12.73 & $1 \cdot 420$ & 3.25 & 0.77 & & & 0.309 & 0.68 \\
\hline FFEB protein & -1.44 & 1.190 & 0.93 & $0 \cdot 112$ & & & 0.091 & $0 \cdot 68$ \\
\hline \multicolumn{9}{|c|}{ Equation: component $\log Y(\mathrm{~g})=a+b \log \mathrm{LW}(\mathrm{g})+c \log \mathrm{BCS}$} \\
\hline Kidney and pelvic fat & $t \quad-11.44$ & 2.760 & $2 \cdot 59$ & 0.782 & $1 \cdot 02$ & $0 \cdot 330$ & $0 \cdot 450$ & $0 \cdot 67$ \\
\hline 'Non-carcass' fat & -19.99 & 5.59 & $0 \cdot 43$ & 0.226 & 2.58 & 0.536 & 0.308 & 0.71 \\
\hline \multicolumn{9}{|c|}{ Equation: component $Y(\mathrm{~g})=a+b \mathrm{LW}(\mathrm{g})+c \mathrm{BCS}$} \\
\hline Carcass fat & -5553 & 1281 & $0 \cdot 15$ & 0.038 & 1515 & 309 & 945 & 0.79 \\
\hline FFEB fat & -10343 & 2017 & 0.32 & 0.061 & 1907 & 485 & 1486 & $0 \cdot 80$ \\
\hline FFEB dry matter & -9386 & 2416 & 0.47 & 0.073 & 1699 & 581 & 1779 & $0 \cdot 82$ \\
\hline
\end{tabular}

Very little variation in ash content was predicted with either BCS or LW. Even the relationship between BCS and ash content in the FFEB was not statistically significant $(P>0.05)$. Likewise, proportionately only $0 \cdot 27$ of the variation in protein content was accounted for by variation in BCS.

Including both $\mathrm{BCS}$ and $\mathrm{LW}$ in the regression equation improved the estimation of dry matter and total fat content. However, despite its statistical significance, little improvement was noted in estimating ash content.

Linear equations were used to compare the relationship of LW and BCS with body composition. However, for the purpose of predicting body composition in Churra ewes, equations giving the best fit to the data, using both BCS and LW (in some cases with logarithmic transformations) are shown in Table 3 .

Table 4 Correlation coefficients for proportion of dissected subcutaneous fat in lumbar joint, proportion of dissected subcutaneous + intermuscular fat in the lumbar joint and body condition score (BCS) and fat depots in mature ewes of Churra breed (all values are significant $(\mathrm{P}<0.05)$ except those indicated with + )

Subcutaneous +

Subcutaneous intermuscular

\begin{tabular}{lll}
\hline BCS & 0.774 & 0.764 \\
Kidney and pelvic fat & 0.693 & 0.679 \\
Omental fat & $0.313 \dagger$ & $0.371 \dagger$ \\
Mesenteric fat & 0.586 & 0.661 \\
Total internal fat & 0.508 & 0.557 \\
'Non-carcass' fat & 0.625 & 0.669 \\
Carcass fat & 0.789 & 0.772 \\
Fleece-free empty body fat & 0.766 & 0.774 \\
\hline \hline
\end{tabular}

As shown in Table 4, the proportions of dissected subcutaneous fat and subcutaneous + intermuscular fat in the lumbar joint were well correlated with carcass fat ( $r=0.789$ and $r=0.772$, respectively) and total fat in the body $(r=0.766$ and $r=0.774$, respectively). Correlation coefficients found between those two depots and individual internal fat depots were lower, especially with the omental depot $(r=$ 0.313 and $r=0.371$, respectively for subcutaneous depot and subcutaneous + intermuscular depot). BCS and proportion of subcutaneous fat in the lumbar joint showed a coefficient of 0.774 . The correlation coefficient between BCS and the proportion of total fat (subcutaneous plus intermuscular) in the lumbar joint dissected was similar $(r=0.764)$.

\section{Discussion}

BCS and LW were correlated with a coefficient of $0.683(P<0.001)$ and logarithmic transformation of the variates did not improve the precision of the equation. The correlation coefficient was lower than expected from previous studies in other breeds (Russel et al., 1969; Purroy et al., 1987; Teixeira et al., 1989; Sanson et al., 1993). However, it was similar to that reported by Oregui (1992) in the Latxa breed. The high variability in adult size and weight observed in sheep of these breeds compared with other breeds might account for this. Thus, the inclusion of both BCS and LW in the prediction model increased, in most equations, the amount of variation accounted for compared with either BCS or LW alone.

The change in LW per unit change in BCS, according to the regression equation, corresponded proportionately to approximately 0.13 of mean live 
weight in Churra ewes. This value is lower than most of the values found in the literature, except again that indicated by Oregui and Garro (1989) in Latxa ewes and the average of three Greek dairy breeds reported by Zygoyiannis et al. (1997) despite the inevitable differences between studies due to the method used for estimating the mature LW, the BCS assessor, etc. Important differences in changes in LW for one unit change in BCS associated with genotype have been reported widely.

The general distribution of mesenteric and kidney and pelvic fat depots was in broad agreement with those indicated by other authors (Russel et al., 1971; Teixeira et al., 1989; Oregui, 1992). However, while others have found that the omental fat depot was markedly increased in animals having BCS higher than three, in Churra ewes, according to the results obtained in this experiment, the omental fat represented the highest proportion of total internal fat regardless of the level of fatness. This may be a characteristic of the breed related to milk production and mobilization of internal fat depots.

Comparisons between breeds must be interpreted carefully since the amounts of fat and their proportions can be very different if they have been determined chemically or by dissection. The amount of total internal fat (dissected) or non-carcass fat (determined chemically) as well as its proportion in the empty body found in Churra sheep was similar to that observed in other milk production breeds and higher than shown by breeds noted for meat production (Russel et al., 1971; Butterfield, 1988). This kind of dichotomy of fat partitioning has been found previously in other sheep breeds (Russel et al., 1972; Butler-Hogg, 1984; Taylor et al., 1989). In general, ewes bred for milk production tend to deposit more fat in internal depots and those bred for meat production deposit more in the carcass depot. Thus, the amount of carcass fat, as a proportion of the carcass weight and as a proportion of the total fat, was also lower than most of the values observed in other breeds and cited in the literature (Wood et al., 1980; Butler-Hogg, 1984; Butterfield, 1988; Taylor et al., 1989).

For BCS over 3, increments in fat depots in Churra ewes were quite low in comparison with higher increments at the highest level of fatness found in other breeds. This may be a characteristic of the Churra breed but it must be noted that there were few animals with scores higher than three which could have affected the reliability of the relationship at the high extreme (see Table 3).

Regressions on LW explained more of the variation than those on BCS for individual internal fat depots and chemically determined non-carcass fat (see Table 2). Only for the kidney and pelvic fat depot, did the inclusion of BCS together with $\mathrm{LW}$ increase the accuracy of the estimation, possibly because this depot is closely associated with the carcass fat which shows a better relationship with BCS.

The prediction of total body fat afforded by LW was better than that provided by BCS. Similar results have been obtained in other breeds, in which LW was a more accurate predictor of body reserves than BCS (Castrillo et al., 1988; Treacher and Filo, 1995). In the ewes of the Churra breed, there are at least two possible explanations for this. On the one hand, the high proportion of non-carcass fat in the total fat and its lower correlation with the BCS than that between BCS and carcass fat, can decrease the accuracy of the BCS as index of prediction. On the other hand, the best results with $\mathrm{BCS}$ have been found in studies including a wide range of BCS values and in animals of a narrow range of sizes. In this experiment, those ranges were narrower and wider, respectively, because they were representative of those generally found in Churra flocks.

LW was by far the best predictor of body protein as has been reported previously (Wright and Russel, 1984). The relationship with the BCS was much poorer since, typically, protein reserves are not depleted to a great extent until animals are very emaciated.

The subcutaneous fat and subcutaneous plus intermuscular fat in the lumbar joint were highly correlated with BCS. They also correlated well with carcass fat and total fat in the body, validating the use of this region for assessing BCS in Churra ewes. Nevertheless, the correlation coefficients were not as high as found in previous studies in other breeds (Delfa et al., 1989). Furthermore, the correlation coefficient found between these fat depots of the lumbar joint and the omental depot was not statistically significant. This lack of correlation may explain the poor relationship found between BCS and internal fat (or non-carcass fat) in ewes of the Churra breed, in which the omental depot plays an important rôle.

The results of this study suggest that BCS was not as accurate for estimating FFEB composition and fat depots in mature ewes of the Churra breed, as has been shown previously in other breeds. This is probably due to the pattern of fat partitioning found in this breed, with a high proportion of the total fat deposited in internal depots. The single most effective prediction index was LW. However, the utilization of both BCS and LW together provided more accurate estimations. 


\section{Acknowledgements}

The authors wish to thank Drs I. A. Wright and A. J. Duncan for helpful comments and revision of the manuscript. This research was supported by the project GAN 90-0906.

\section{References}

Agricultural Research Council. 1980. The nutrient requirements of ruminant livestock. Commonwealth Agricultural Bureaux, Slough.

Association of Official Analytical Chemists. 1984. Official methods of analysis, 14 th edition. Association of Official Analytical Chemists, Arlington, VA.

Butler-Hogg, B. W. 1984. The growth of Clun and Southdown sheep: body composition and the partitioning of total body fat. Animal Production 39: 405-411.

Butterfield, R. M. 1988. New concepts of sheep growth. The Department of Veterinary Anatomy, University of Sydney.

Castrillo, C., Baucells, M. and Guada, J. A. 1988. Relationship between body fat reserves and body condition score in sheep at different physiological stages. Animal Production 46: 514 (abstr.).

Delfa, R., Teixeira, A. and Colomer-Rocher, F. 1989. A note on the use of a lumbar joint as a predictor of body fat depots in Aragonesa ewes with different body condition scores. Animal Production 49: 327-329.

Jefferies, B. C. 1961. Body condition scoring and its use in management. Tasmanian Joumal of Agriculture 32: 19-21.

Lawes Agricultural Trust. 1993. Genstat 5, release 2.2. Rothamsted Experimental Station, Harpenden.

McClelland, T. H. and Russel, A. J. F. 1972. The distribution of body fat in Scottish Blackface and Finnish Landrace lambs. Animal Production 15: 301-306.

Murray, J. A. 1919. Meat production. Joumal of Agricultural Science, Cambridge 9: 174-181.

Oregui, L. M. 1992. [Study of the feeding management in sheep flocks of Latxa breed and its effect on reproduction and milk production]. Serv. Central Publicac., Gobierno Vasco. Tesis doctorales no. 18. Victoria-Gasteiz.

Oregui, L. M. and Garro, J. 1989. [Evolution of body condition in sheep of Latxa breed during the summer grazing season and relationship with live weight]. ITEA 9: (supplement) 125-127.

Purroy, A., Sebastián, I. and Baucells, M. 1987. [Relationship between body condition score and some parameters for estimating body composition in ewes of Rasa Aragonesa and F1 (Romanov $\times$ Rasa Aragonesa)]. In Les cascasses d'agneaux et de cheoreaux mediterranées. Rapport EUR 11479, CEE, Luxemburg, pp. 145-157.

Russel, A. J. F., Doney, J. M. and Gunn, R. G. 1969 Subjective assessment of fat in live sheep. Journal of Agricultural Science, Cambridge 72: 451-454.

Russel, A. J. F., Doney, J. M. and Gunn, R. G. 1971. The distribution of chemical fat in the bodies of Scottish Blackface ewes. Animal Production 13: 503-509.

Sanson, D. W., West, T. R., Tatman, W. R., Riley, M. L. Judkins, M. B. and Moss, G. E. 1993. Relationship of body composition of mature ewes with condition score and body weight. Joumal of Animal Science 71: 1112-1116.

Taylor, St C. S., Murray, I. I. and Thonney, M. L. 1989 Breed and sex differences among equally mature sheep and goats. Animal Production 49: 385-409.

Teixeira, A., Delfa, R. and Colomer-Rocher, F. 1989 Relationship between fat depots and BCS or tail fatness in the Rasa Aragonesa breed. Animal Production 49: 275-280.

Treacher, T. T. and Filo, S. 1995. Relationship between fat depots and body condition score or live weight in Awassi ewes. Options Mediterranees 27: 19-24.

Wood, J. D., MacFie, H. J. H., Pomeroy, R. W. and Twinn, D. J. 1980. Carcass composition in four sheep breeds: the importance of type of breed and stage of maturity. Animal Production 30: 135-152.

Wright, I. A. and Russel, A. J. F. 1984. Estimation in vivo of the chemical composition of bodies of mature cows. Animal Production 38: 33-44.

Zygoyiannis, D., Stamataris, C., Friggens, N. C., Doney, J. M. and Emmans, G. C. 1997. Estimation of the mature weight of three breeds of Greek sheep using condition scoring corrected for the effect of age. Animal Science 64: 147-153.

(Received 2 September 1996_Accepted 21 November 1996) 